\title{
Double heterostructure lasers with facets formed by a hybrid wet and reactive-ion-etching technique
}

\author{
J. Saizman, T. Venkatesan, ${ }^{\text {a) }}$ S. Margalit, and A. Yariv \\ California Institute of Technology Pasadena, California 91125
}

(Received 21 September 1984; accepted for publication 4 December 1984)

\begin{abstract}
Double heterostructure lasers were fabricated in which one of the laser facets was produced by a hybrid wet and reactive-ion-etching technique. This technique is suitable for GaAs/GaAlAs heterostructure lasers and utilizes the selectivity of the plasma in preferentially etching GaAs over GaAlAs. Lasers fabricated by this technique are compatible with optoelectronic integration and have threshold currents and quantum efficiency comparable to lasers with both mirrors formed by cleaving. The technique enables the use of relatively higher pressures of noncorrosive gases in the etch plasma resulting in smoother mirror surfaces and further eliminates the nonreproducibility inherent in the etching of GaAlAs layers.
\end{abstract}

The desirability of providing lasers on large-area substrates, ${ }^{1-3}$ which contain both optical and electronic components require the development of batch processing techniques. To make use of a large-area chip, the laser feedback must be provided by techniques other than cleaving. Distributed feedback structures have been explored ${ }^{4,5}$ and wet chemical etching ${ }^{6-9}$ has also been used to define laser mirrors, but undercutting and orientation selectivity are inherent constraints. Recently reactive-ion-etching (RIE) techniques have been successfully used to fabricate $e^{10-13}$ feedback facets in quaternary lasers. Because of the recognized technological importance of the $\mathrm{GaAs} / \mathrm{GaAlAs}$ system it would be desirable to extend these ideas to this system as well. $\mathrm{GaAs}$ has been etched by RIE, ${ }^{14,15}$ but there has been no report of similar work in GaAs/GaAlAs lasers, presumably because of the difficulty involved in the etching of GaAlAs. A gas mixture of $\mathrm{BCl}_{3}$ and $\mathrm{Cl}_{2}$ has been used ${ }^{16}$ to etch $\mathrm{GaAlAs}$ though the oxidation of GaAlAs makes the etching process difficult to reproduce. Recently, reactive ion assisted chemical etching of GaAs/GaAlAs was demonstrated ${ }^{17}$ but reproducible etching required ultra-high-vacuum conditions $\left(<10^{-9}\right.$ Torr base pressure). In this paper we describe a novel hybrid wet and dry etching technique which enables high aspect ratio structures in GaAs/GaAlAs heterostructures which form good feedback structures for laser devices. The technique utilizes noncorrosive gases in the plasma, is reproducible and yields surfaces which are smoother than those produced by conventional RIE of GaAs/GaAlAs layers.

In the case of $\mathrm{GaAs} / \mathrm{GaAlAs}$ high selectivity in the etshing using a freon- 12 plasma has been demonstrated. ${ }^{18}$ Further, using a mixture of freon- $12\left(\mathrm{CCl}_{2} \mathrm{~F}_{2}\right)$, helium and oxygen we have obtained good etch rates $(\sim 0.1-0.5 \mu \mathrm{m} /$ min) with vertical walls in GaAs even at pressures as high as $15 \% 20 \mu \mathrm{m}$. At these pressures the GaAlAs on the surface is etched at a rate which is more than one order of magnitude smaller than that of GaAs. The high-pressure etching has a further advantage-generally increasing gas pressures and

\footnotetext{
'Bell Communications Research, Murray Hill, New Jersey 07974.
}

the lowering of substrate temperatures leads to smoother etching.

We have made use of this selectivity in making laser facets, by first wet etching grooves (with orientational preference) in the heterostructures and then using the edges of the etched GaAlAs layers as masks in the dry etching of the GaAs active layer. As illustrated in Fig. 1(a), to the double heterostructure $(\mathrm{DH})$ grown by liquid-phase epitaxy a thin $\mathrm{Ga}_{0.5} \mathrm{Al}_{0.5}$ As layer is added at the top for protecting the $\operatorname{GaAs}\left(p^{+}\right)$contact layer during the $\mathrm{RIE}$. The layers are wet etched using a mixture of $\mathrm{H}_{2} \mathrm{SO}_{4}, \mathrm{H}_{2} \mathrm{O}_{2}$ and $\mathrm{H}_{2} \mathrm{O}$, resulting in orientation dependent profiles. When the (100) plane of $\mathrm{GaAs}$ is etched with mask openings oriented along the [011] or [011] directions, the groove profiles are determined by the preferential etching of (111) and (11i) planes ( $\mathrm{V}$ groove) or of the (111) and (i11) planes (dovetail groove), respectively. ${ }^{19}$ We found that when a DH is etched in the $\mathrm{H}_{2} \mathrm{SO}_{4}-\mathrm{H}_{2} \mathrm{O}_{2}-\mathrm{H}_{2} \mathrm{O}$ system, the angle of the groove sidewalls changes with $\mathrm{Al}$

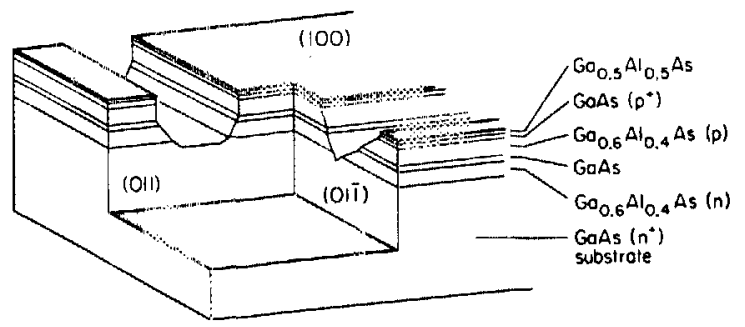

(a)

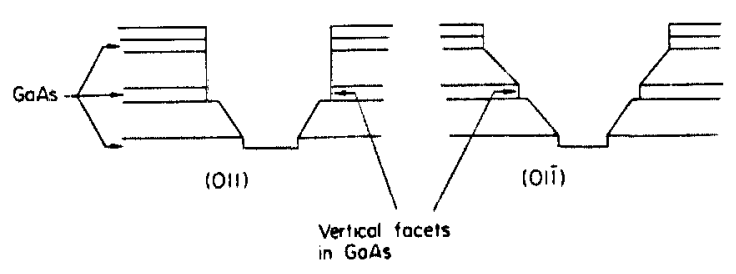

(b)

FIG. 1. General scheme of the hybrid wet and dry etching scheme: (a) Groove profiles that can be obtained when the $(100)$ face of a $D H$ is preferentially etched with a $\mathrm{H}_{2} \mathrm{SO}_{4}-\mathrm{H}_{2} \mathrm{O}_{2}-\mathrm{H}_{2} \mathrm{O}$ solution. Note that the $\mathrm{GaAs}$ is not etched vertically either in the (011) or the (01) direction (b) Groove profiles after RIE, showing vertical walls in GaAs. 


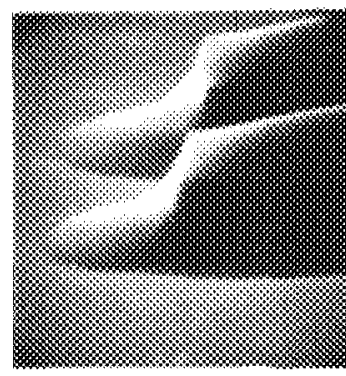

(a)
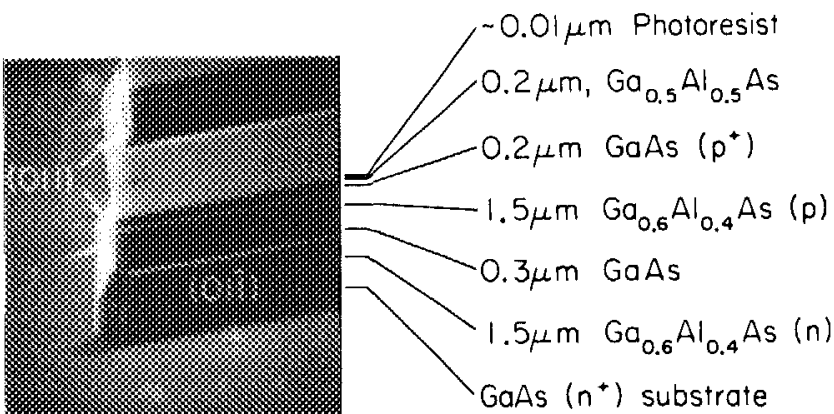

(b)
†

concentration, the etchant composition and the etching temperature. For $\mathrm{Ga}_{0.6} \mathrm{Al}_{0.4}$ As etched with $\mathrm{H}_{2} \mathrm{SO}_{4}: \mathrm{H}_{2} \mathrm{O}_{2}(30 \%$ by weight): $\mathrm{H}_{2} \mathrm{O}(1: 8: 10)$ at $25^{\circ} \mathrm{C}$ we obtained near vertical profiles along the $(01 \overline{1})$ direction in the GaAlAs upper cladding layer. The GaAs active layer is etched with a positive slope $^{20}$ as shown in Fig. 1(a). The sample is then etched in a plasma under the conditions described above. The GaAlAs layers act as masks and the GaAs layers are etched with a vertical profile [Fig. 1(b)]. Because of the higher pressures under which the layer is etched, we expect the facet to have a smoother surface. This technique is most suitable when the active layer is thick $(>0.3 \mu \mathrm{m})$ so that a significant portion of the lasing mode is confined in the active layer. With the perpendicularly wet etched top cladding layer the effective reflectivity of the facet is further improved.

After the DH layer is grown by LPE, the wafers are patterned with AZ1350I photoresist with openings for the mirrors. The resist is hard baked to prevent significant undercutting and to promote adhesion. The mirror groove is wet etched by using the $1: 8: 10$ etch solution, and the sample is then reactive ion etched in a diode plasma etch station. The top and bottom electrodes were covered with 6-in. diam silicon wafers. An etch gas consisting of freon-12: $\mathrm{He}_{\mathrm{C}} \mathrm{O}_{2}$ was used at a pressure of $15-20 \mu \mathrm{m}$ at a plasma power density of
$0.15 \mathrm{~W} / \mathrm{cm}^{2}$. The GaAs etch rate was $0.2 \mu \mathrm{m} / \mathrm{min}$ under these conditions. We found that by utilizing a $1 / 16 \mathrm{in}$. thick quartz plate over the bottom electrode, the etch rate increased by over a factor of two under identical conditions.

In Fig. 2 are shown the scanning electron microscope cross sections of some devices before and after the reactive ion etching. In this case, etching in both the (011) and the $(01 \overline{1})$ directions are shown. In the (01) plane the GaAlAs is nearly vertically wet etched (Fig. 2a). After the plasma etching, good vertical facets are obtained near the contact layer, active layer and the substrate. In all these regions the GaAlAs upper layers act as a plasma etch mask. In Fig. 3(a) magnified image of the etched GaAs region is shown indicating nonuniformities on the scale of $<500 \AA$. At lower pressures ( $\sim 5 \mathrm{mTorr}$ ), required to etch GaAlAs, the etched surfaces would be significantly rougher illustrating the advantage of this higher pressure technique. After etching vertical walls in the GaAs (active) layer by RIE, a further chemical polishing was done by a dip etch in $\mathrm{H}_{2} \mathrm{SO}-$ ${ }_{4}: \mathrm{H}_{2} \mathrm{O}_{2}: \mathrm{H}_{2} \mathrm{O}(4: 1: 1)$. Oxide stripe lasers were then fabricated from wafers prepared in this way.

Figure 4 shows the light intensity of the cleaved facet of comparable devices, where some lasers had both mirrors cleaved and some had one of the facets reactive ion etched.

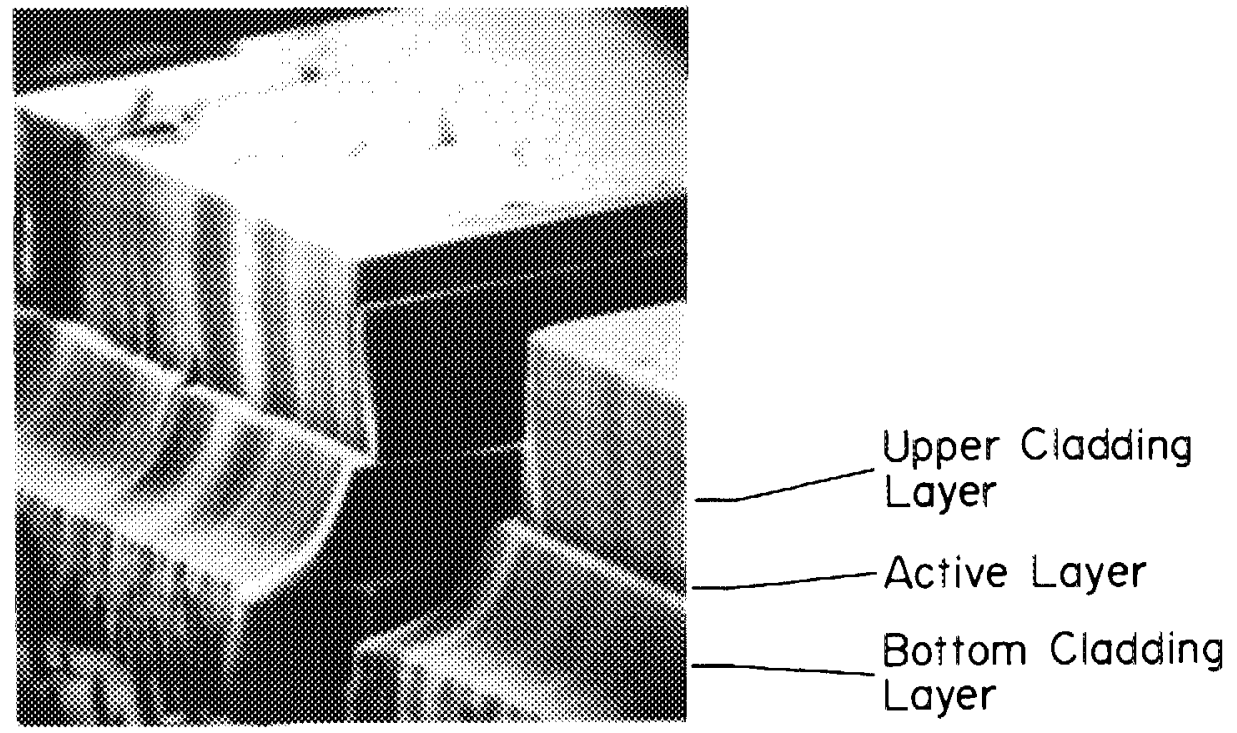

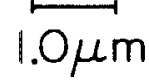

FIG. 3. A magnified view of the facet surface revealing nonuniformities of $<500$ $\AA$. 


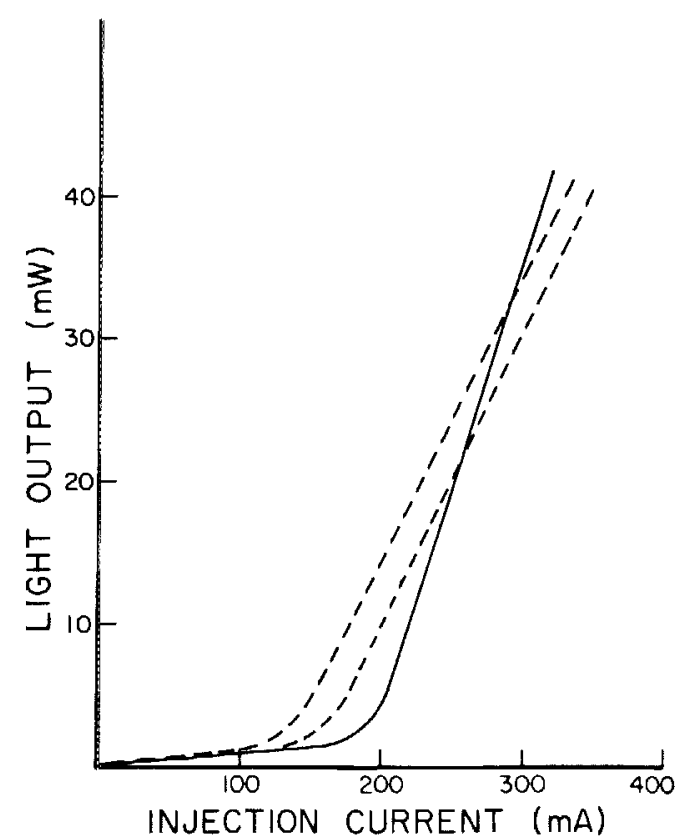

FIG. 4. Light intensity vs laser current for various lasers (-) with both cleaved facets (--) with one facet etched.

The threshold currents in lasers with both mirrors cleaved and those with one of the facets reactive ion etched were comparable (within 10\%), and were reasonable on account of the thick active layers used in these devices. The quantum efficiency of these lasers were comparable as well, indicating an adequately well-etched mirror. These results were obtained in a large number of devices fabricated from different wafers, indicating a high degree of reproducibility. The mirrors produced by this method provide for laser feedback with lower reflectivity at the cladding layers than that of the active layer so that highly confined ficlds would be the preferred lasing modes. Therefore, the fundanental transverse mode is favored even for very thick active layers. In this case, the slopes in the GaAlAs cladding layers have a minor inftuence in the laser operation, allowing for use orientations other than that of the (011) for the laser mirrors. By this technique, mirrorlike facets with different curvatures can be fabricated as well. In fact, unstable resonator cavity lasers with both curved mirrors formed by etching were also demonstrated. ${ }^{21}$ These lasers had threshold current and external quantum efficiency in good agreement with theoretical predictions in which the mirror reflectivity was assumed to be the same as that of cleaved facets.
In summary, we have described the successfull operation of a simple DH laser fabricated using a hybrid wet- and dry-etching technique. This technique may prove useful in the fabrication of other laser device geometries, the integration of the lasers with other electronic, or optical devices and components on the same wafer.

This research is supported by grants from the National Science Foundation and the Office of Naval Research. We would like to thank E. Kapon and Z. Rav-Noy for advice in the fabrication techniques. J. Salzman would like to acknowledge the support of the Bantrell post-doctoral fellowship.

'J. L. Merz, R. A. Logan, and A. M. Sargent, IEEE J. Quantum Electron. QE-15, 72 (1979).

${ }^{2}$ K. Kishina, Y. Suematsu, K. Utaka and H. Kawanishi, Jpn. J. Appl. Phys. $17,589(1978)$.

${ }^{3}$ I. Ury, S. Margalit, M. Yust and A. Yariv, Appl. Phys. Lett. 34, 430 (1979).

4A. Yariv and M. Nakamura, IEEE J. Quantum Electron. QE-13, 233 (1977).

${ }^{5}$ M. Sargent III, W. H. Swantner, and J. D. Thomas, IEEE J. Quantum Electron. QE-16, 465 (1980).

${ }^{\circ}$ K. Iga, T. Kambayashi, K. Wakao, and Y. Sakamoto, Jpn. J. Appl. Phys. 18, 2035 (1979).

7P. D. Wright, R. J. Nelson, and T. Cella, Appl. Phys. Lett. 36, 518 (1980).

${ }^{8}$ K. Iga, M. A. Pollock, B. I. Miller, and R. J. Martin, IEEE J. Quantum Electron. QE-16, 1044 (1980).

${ }^{9} \mathrm{~K}$. Iga and B. I. Miller, Electron. Lett. 16, 342 (1980).

${ }^{10}$ L. A. Coldren, K. Iga, B. I. Miller, and J. A. Rentschler, Appl. Phys. Lett. 37, $681(1980)$

"L. A. Coldren, B. I. Miller, K. Iga, and J. A. Rentscher, Appl. Phys. Lett. 38, 315 (1981).

${ }^{12}$ L. A. Coldren and J. A. Rentscher, J. Vac. Sci. Technol. 19, 225 (1981).

${ }^{13}$ L, A. Coldren, K. Furuya anto B. I. Miller, J, Electrochem. Soc. 130, 1918 (1983).

${ }^{14}$ E. L. Hu and R. E. Howard, A.ppl. Phys. Lett. 37, 1022 (1980).

${ }^{15}$ P. Buchman, H. Kaufman, KI. Melchior, and G. Guekos, Electron. Lett. 20. 295 (1984)

${ }^{16}$ L. A. D Asaro, A. D. Butherus, J. V. DiLorenzo, and S. H. Wemple, Intertational Symposium on Gallium Arsenide and Related Compounds, Viernos, Austria (Sept. 22, 1980).

${ }^{17}$ K. Asakawa and S. Sugata, Jpn. J. Appl. Phys. 22, L653 (1983).

${ }^{18}$ K. Hikosaka, T. Mimura and K. Joshin, Jpn. J. of Appl. Phys. 20, L847 (1981).

${ }^{19}$ W. T. Tsang and S. Wang, Appl. Phys. Lett. 28, 44 (1976)

${ }^{20}$ In the late stages of the preparation of this manuscript we became aware of a recent report of vertical facets produced on $\mathrm{DH}$ structures (with $\mathrm{Al}_{0.4}$ in the cladding layers) using a similar wet etchant. $M$. Wada, $K$. EXamada, $K$. Etoh, and G. Kano, paper presented at the Ninth IEEE International Semiconductor Laser Conference, Rio de Janeiro, Brazil (Augus: 7, 1984).

${ }^{2}$ R. Salzman, T. Venkatesan, R. Lang, M. Mittelstein and A. Yariv, Appl. Phys. Lett. 46, (1985). 